\title{
Nuevos ensanches: análisis comparado en cuatro ciudades medias del noroeste español
}

Sergio Tomé. Universidad de Oviedo, Oviedo, España.

RESUMEN | La falta de una visión de conjunto determina que desconozcamos en gran medida el resultado de la aplicación de los modelos de urbanización compacta en ciudades de tamaño medio, que ha tenido lugar desde finales del siglo xx. Tal situación deriva en diagnósticos muy generalistas, basados sobre todo en las grandes aglomeraciones. Aquí se ofrece una comparativa entre cuatro poblaciones españolas de categoría intermedia, geográficamente cercanas, donde fueron promovidos durante el cambio de siglos grandes polígonos de viviendas, emparentables aunque diferenciados. Mediante un acercamiento transversal, numérico y cualitativo, a variables morfológicas, económicas, relativas a la comunidad y el medioambiente, se valora el peso de los factores locales en el modelado urbano final. La investigación demuestra que, a esa escala de análisis, aflora una considerable diversidad de situaciones y una serie amplia de aspectos mejorables, con los cuales el balance resulta desfavorable en términos de sostenibilidad.

PALABRAS CLAVE | urbanismo, geografía urbana, desarrollo sustentable.

ABSTRACT | There is an absence of a general vision that can allow us to know enough about the results of the application of compact urbanization models in middle-sized cities since the end of the twentieth century. Such a situation causes us to conduct very general diagnoses, supported above all in large agglomerations. In this article, we compare four Spanish cities of medium category, geographically close, in which large housing complexes were built during the transition from the twentieth to the twenty-first century, with similarities and differences. The approximation is transversal, numerical and qualitative. It relates the morphological, economic, community and environmental aspects, to measure the incidence of the local factors in the resulting urban product. The research shows that the analysis scale we use allows us to determine a diversity of situations and the improvable aspects of urban planning, which are not satisfactory in terms of sustainability.

KEYWORDs | urbanism, urban geography, sustainable development.

Recibido el 11 de mayo de 2019, aprobado el 30 de septiembre de 2019.

E-mail: stome@uniovi.es 


\section{Introducción}

La expansión inmobiliaria española entre 1998 y 2007 ayudó a imponer el paradigma urbano posfordista, en forma de sprawl o a través de morfologías relativamente compactas (Burriel, 2008, 2015; Campos Echevarría, 2008; Romero, 2010). Allí como en otros países, la ciudad ha sido el campo de pruebas para las políticas de privatización, inversión especulativa y reconversión clasista (Harvey, 2007; Theodore, Peck, \& Brenner, 2009). Lo más sustancial de ese modelo neoliberal es la fragmentación física, la dispersión de usos y una creciente separación de grupos sociales (Borsdorf \& Hidalgo, 2010; Escolano, López, \& Pueyo, 2018; Pinson \& Morel Journel, 2016). Por su novedad y enorme incidencia, tanto espacial como ambiental, los geógrafos y otros urbanistas han prestado más atención a la ciudad difusa que a los desarrollos en forma de ensanche, con vivienda colectiva, yuxtapuestos al continuo urbano o formando islas (Brandis, 2007; López de Lucio, 2004; Valdunciel, 2013). En uno u otro caso han primado las aproximaciones de carácter general o centradas en las metrópolis, grandes capitales regionales y zonas turísticas, mientras lo ocurrido en núcleos de tamaño intermedio es menos conocido (Brandis, 2012; Campesino, 2014; Jiménez, Hidalgo, Campesino, \& Alvarado, 2018).

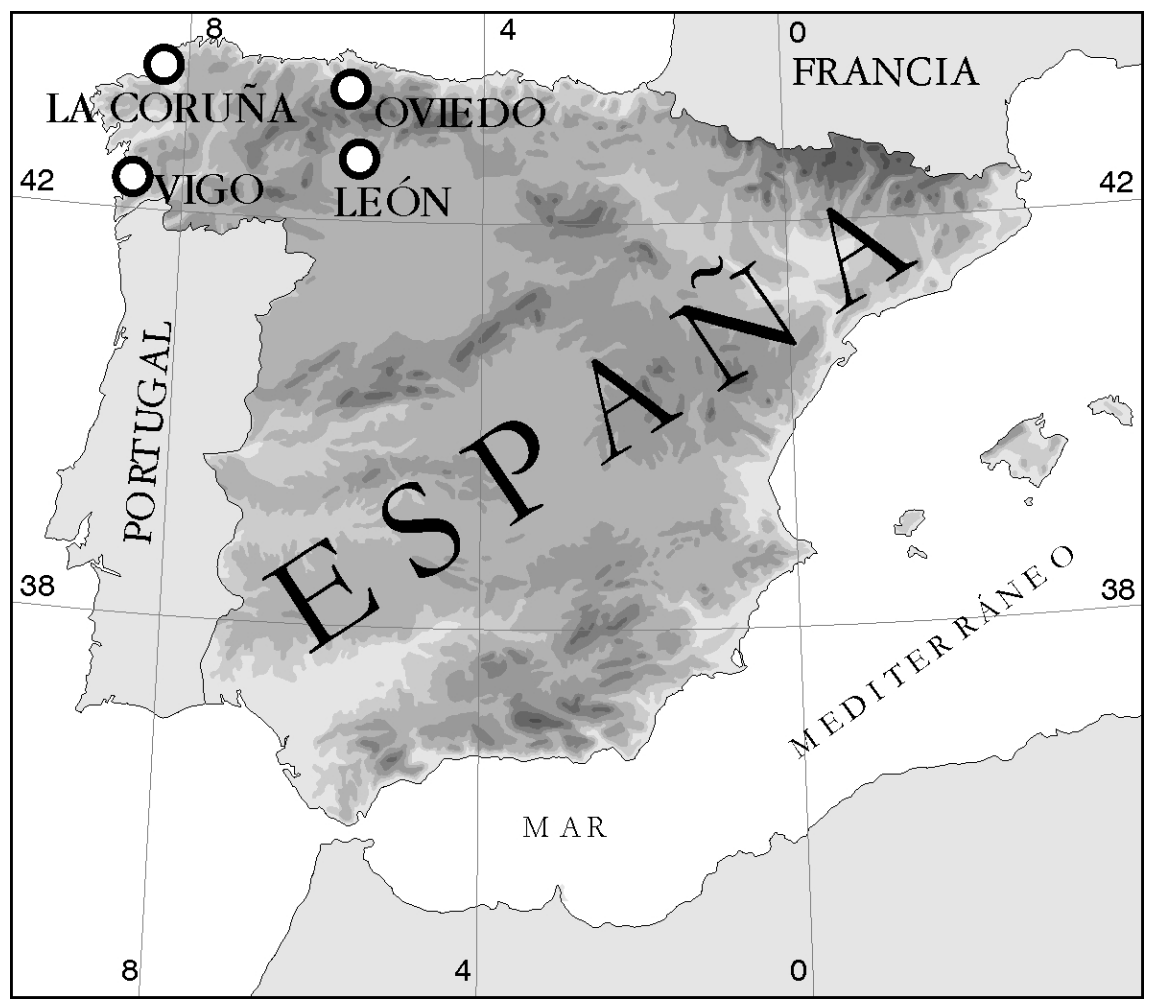

FIGURA I | Localización de las ciudades estudiadas

FUENTE: ELABORACIÓN PROPIA 
Atendiendo a esa circunstancia, lo que aquí se aporta es una valoración conjunta de los principales proyectos residenciales acometidos, entre la burbuja y la crisis, en cuatro ciudades de rango medio bajo (La Coruña, León, Oviedo y Vigo), situadas en la región noroccidental de España (figura 1). La envergadura de los polígonos y sus atributos de "nueva ciudad", bien individualizada en la percepción ciudadana, hacen de ellos organismos ricos, con indudable personalidad geográfica, relativamente complejos en su gestación, resolución morfológica y ordenación funcional. La correspondencia cronológica y de magnitudes entre los casos analizados, así como sus evidentes paralelismos, permiten la comparación con una cierta perspectiva temporal, ya que los procesos de desarrollo están prácticamente cerrados. En casi todos los casos se han añadido posteriormente, o están en curso, otros espacios residenciales anejos, que por razones de coherencia se dejan fuera del estudio. La investigación se centra en la forma física, el reparto de usos, los aspectos sociodemográficos y las dimensiones ambientales. Es, por tanto, una observación integral, que contrapone las buenas prácticas con los aspectos mejorables en términos de desarrollo sostenible. El método aplicado consistió en la búsqueda de relaciones entre la información numérica y la de carácter cualitativo, utilizando las formas de paisaje como vía de aproximación al esquema compositivo, la lógica y la estructura interna de cada polígono. El paso siguiente fue el establecimiento del denominador común y las especificidades en los casos de estudio, para recoger la diversidad de respuestas a las exigencias del crecimiento urbano.

La información utilizada procede de los reconocimientos de campo, la consulta de materiales de planeamiento y la revisión bibliográfica, así como el trabajo de hemeroteca, la recogida de estadísticas y entrevistas a veinte ciudadanos de distinta condición en cada núcleo, utilizando un cuestionario abierto. La hipótesis de partida sostiene que, en materia de nuevos desarrollos urbanos, las ciudades medias no solo confirman lo ya comprobado en las grandes aglomeraciones (Ayuntamiento de Madrid, 2006; Brandis, 2018; Egea Reche, 2000). Al variar la escala entran en juego especificidades, aparecen cambios de significado por la mayor relevancia de esos distritos dentro de su contexto, y aflora una casuística diversa que obliga a matizar las interpretaciones generalistas. En efecto, los factores locales y las dinámicas del entorno geográfico introducen variaciones notables en el resultado material del crecimiento en continuo, como también las políticas urbanas municipal y regional condicionan la satisfacción de cada polígono y su comportamiento en el tiempo. La elección de las cuatro ciudades no obedece solo a la cercanía física con el investigador, lo que le permite trabajar sobre el terreno. También existe una justificación metodológica, pues son poblaciones de importancia equivalente, en territorios que han sufrido reconversiones económicas (industrial, minera, agraria). De ahí que tengan en común su estancamiento o declive demográfico (León es una shrinking city, que perdió 23.000habitantes entre 1991 y 2018), el retroceso de la industria (excepto en La Coruña, vinculada con la empresa Zara) y la consiguiente terciarización, favorable a las periferias, así como un innegable aumento de la desigualdad social (Precedo \& Míguez, 2014). ${ }^{1}$

1 Según Eurostat.database, sus tamaños demográficos fluctúan entre 124.000 y 293.000 habitantes, y los de sus áreas urbanas funcionales entre 209.000 y 542.000, con datos de 2018. 
Los proyectos urbanos que aquí se consideran, cuyo detalle aparece en la tabla 1, atendieron distintas finalidades. En unos casos (La Coruña, León) ejecutaban con retraso y reformas sustanciales el planeamiento heredado de los años 1960-1970 (Cortes de Castilla y León, 1993). De manera universal alimentaron la principal fuente de ingresos de los Ayuntamientos, facilitaban el movimiento de capitales, la canalización del ahorro y -al menos en cierto grado- el crecimiento de la burbuja inmobiliaria. Avivar la economía local, orientándola equivocadamente hacia la construcción, fue un objetivo tanto o más destacado que atender las necesidades de alojamiento, fomentando las viviendas protegidas y la intervención de las cooperativas. A ello debe sumarse el deseo de neutralizar el trasvase de población hacia los municipios periféricos, y atraer efectivos escapados del medio rural o las comarcas mineras reconvertidas, en Asturias y León.

\begin{tabular}{|l|c|l|l|l|}
\hline $\begin{array}{c}\text { CIUDAD/ } \\
\text { DENOMINACIÓN DEL } \\
\text { POLÍGONO }\end{array}$ & $\begin{array}{c}\text { SUPERFICIE } \\
(\mathbf{H A})\end{array}$ & VIVIENDAS & \multicolumn{1}{|c|}{ PROMOTOR } & $\begin{array}{c}\text { FECHAS INICIO } \\
\text { Y CULMINACIÓN }\end{array}$ \\
\hline La Coruña-Los Rosales & 51,6 & 3.500 & Los Rosales & $1970-1991-2001$ \\
\hline León-Eras de Renueva & 80 & 4.800 & Gesturcal & $1961-1993-2010$ \\
\hline Oviedo-La Corredoria & 63 & 4.592 & Sogepsa & $1997-2009$ \\
\hline Vigo-Navia & 72,8 & 3.458 & IGVS & $1996-2005$ \\
\hline
\end{tabular}

NOTA GESTURCAL: GESTIÓN URBANÍSTICA DE CASTILLA Y LEÓN S.A.; SOGEPSA: SOCIEDAD DE GESTIÓN Y PROMOCIÓN DE SUELO DE ASTURIAS; IGVS: INSTITUTO GALEGO DE VIVENDA E SOLO.

TABLA I | Fichas de los polígonos

FUENTE: ELABORACIÓN PROPIA

\section{Los patrones urbanísticos y edificatorios}

Puede formularse el axioma de que la morfología urbana introducida en los grandes conjuntos analizados tuvo, como principal condicionante, la superficie del terreno disponible y su figura, más apropiada para composiciones longitudinales o masivas. En algún caso fue forzosa la adaptación a estructuras previas, como las vías de gran capacidad (Oviedo, Vigo) laterales al nuevo asentamiento, que facilitan el acceso pero también lo aíslan o devalúan ciertas partes del mismo. El bastidor natural, llano o coincidente en La Coruña con un pequeño valle en anfiteatro, de grandes posibilidades paisajísticas, es siempre favorable, de manera que a la hora de establecer interacciones resulta una variable de menos peso que la posición relativa dentro de la ciudad. Todos los polígonos son periféricos salvo el de León, cuya parte mejor situada es pericentral, contigua al ensanche burgués de 1904 (como el polígono de Lezkairu en Pamplona, por citar algún otro ejemplo), de donde deriva su carácter especial. He ahí la excepción a una regla según la cual el entorno de esas grandes piezas estaba previamente definido, incluso en las márgenes laterales de León, por formas de aprovechamiento y contenidos heterogéneos, menos cualificados de lo que se incorporará después. Había manchas de vivienda unifamiliar, naves, alojamiento 
social y autoconstrucción modesta, además de elementos de rechazo, como un cementerio o zonas industriales relativamente próximas (Vigo, Oviedo).

Los proyectos no siempre han logrado una permeabilidad suficiente o una soldadura satisfactoria con los espacios circundantes. Las preexistencias solo se incorporaron físicamente al nuevo tejido en la capital de Asturias, pues el polígono de La Corredoria envuelve el pequeño barrio de La Carisa, el mayor núcleo de viviendas sociales de la ciudad (Vallina, 1999). Herencias de esa naturaleza suelen producir afección negativa sobre las rentas inmobiliarias de las áreas próximas, como ocurre allí, aunque otras veces el estrato urbano más moderno revaloriza la zona, condena los elementos del pasado a una condición relicta, o los coloca en expectativa de derribo (León).

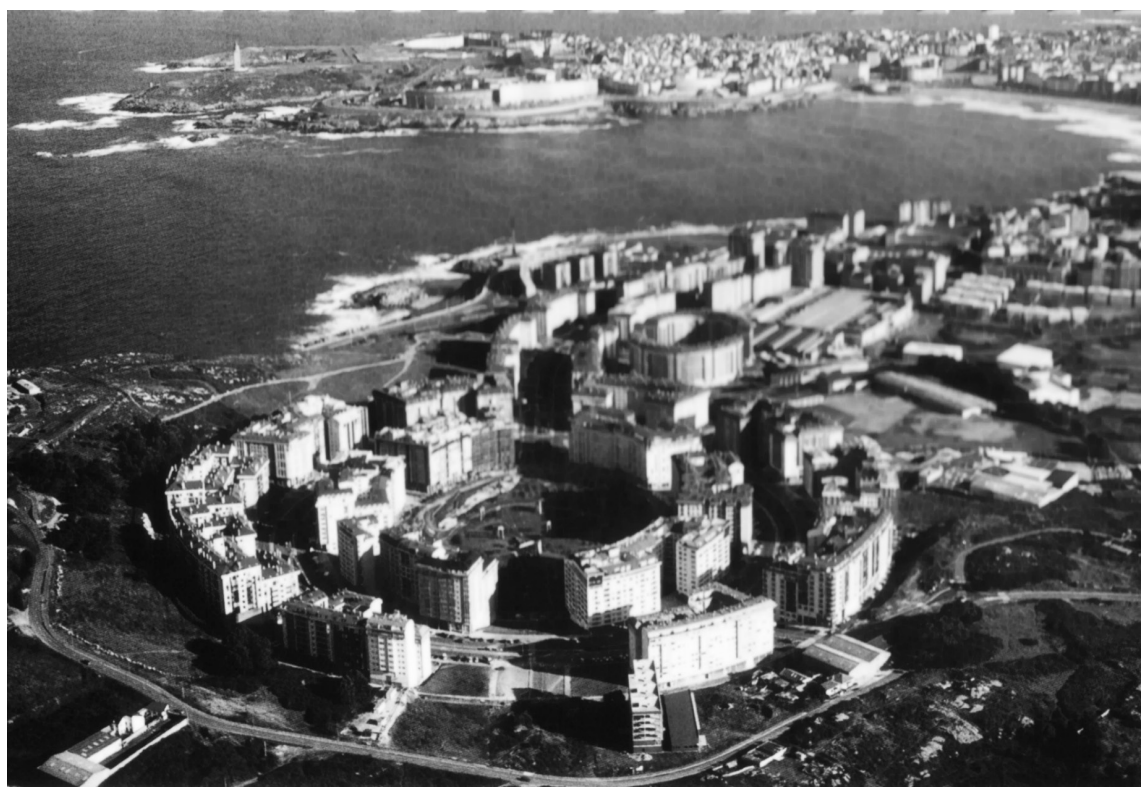

Figura 2 | Polígono Los Rosales (La Coruña)

FUENTE: AYUNTAMIENTO DE LA CORUÑA, AEROVISTAS, 2004

Las densidades medias (47,5 viviendas/hectárea en Vigo, y entre 60 y 72 en las otras) son adecuadas, aunque no necesariamente suponen unas condiciones de esponjamiento uniformes. En su base, los sistemas viales recogen la influencia del sprawl, en forma de anillos, adaptados a condiciones de compacidad (Parker, 2015; Verderber, 2012). Pero la fuente de inspiración más directa parece encontrarse en el Plan General de Madrid de 1997, más precisamente algunos Planes de Actuación Urbanística (PAU) como Sanchinarro o Las Tablas, de donde tal vez toman los trazados circulares o semicirculares concéntricos, y acaso el reparto de espacios y volúmenes (De la Riva, Palacios \& Vinuesa, 2011; López de Lucio, 2007). La aspiración de un urbanismo virtuoso ha legado diseńos vistosos, de raqueta (La Coruña, figura 2) o boomerang (Vigo), emparentables con el proyecto madrileño de Montecarmelo 
(Brandis, 2012; Grupo TAU \& Liñeiro, 2016). Un bulevar de latitud importante (28-42 metros) actúa como articulador en esos proyectos y en el de Eras de Renueva, donde la linealidad del suelo de base (500 metros de anchura máxima, por 1570 de fondo) justifica una formación uniforme de bloques en bandas (Moreno, s.f.). El plano de La Corredoria es el único mixto, tiene una primera fase ortogonal mal vertebrada con los anillos semicirculares de la segunda, sin una vía amplia de contacto más allá de la antigua carretera nacional (AS-266). La insuficiente jerarquización de la red arterial, y los recorridos en arco, producen allí un efecto de laberinto para los automovilistas (Gayo, 2013, Obeso, 2018).

El bulevar colector, las glorietas y en su caso (Oviedo, La Coruña) grandes plazas redondas o elípticas, cuya dimensión rebasa las 3 hectáreas, suman, con los demás espacios públicos y zonas verdes ( 8 hectáreas en Vigo y Oviedo), porcentajes considerables de terreno libre (20-30\%). Hay una distribución bastante armónica de las partes edificadas y las superficies descubiertas en Oviedo y en el polígono coruñés de Los Rosales, donde los bloques de viviendas se alinean con el eje central (Manuel Azaña) y forman un doble círculo alrededor de la plaza-jardín. En los otros casos las zonas construidas resultan muy masivas: veintiún inmuebles en dos hileras, con alzados entre diez y dieciséis pisos, separados por estrechos espacios peatonales, dan a la rúa Teixugueiras de Vigo $(1,8 \mathrm{~km})$ cierto aire de zanja. Aunque con menos altura, también en León la avenida Reyes Leoneses queda enmarcada por un frente edificado casi en continuo, con cuerpos de gran desarrollo horizontal hacia las vías laterales, algunas de ellas en fondo de saco, por lo que producen la impresión de un entorno cerrado (López de Lucio, 2004). La primacía de esas arterias mayores generadoras de urbanidad, con el apoyo en Galicia de soportales que les confieren unidad, no es menos destacable que el manejo de diferentes combinaciones entre bloques y torres. Aparecen aislados, en línea o agrupados en manzana abierta o semiabierta, permitiendo obtener espacios públicos de distinto tamaño y función: interbloques, en núcleo de manzana o superficies mayores, bien sean franjas laterales o de separación entre ámbitos diferenciados.

Adicional a lo expuesto, el contexto en que se desarrollaron esas grandes promociones no favoreció la experimentación arquitectónica, fuera de los proyectos singulares. En proporción directa a su precio, el aspecto de la edificación ha mejorado sustancialmente en comparación con la época tardofranquista e incluso posterior. Ello obedece en parte a la alternancia de materiales y el recurso del color, aunque también se practica en exceso un revival de las casas burguesas de miradores, y se reproducen tipologías racionalistas de los ańos treinta. Los alojamientos de nivel medio e inferior suelen ser más monótonos, cercanos a la pura construcción, con exceso de ladrillo a la vista (en Asturias y León) que empobrece la imagen urbana. Si son anteriores al Código Técnico de Edificación (2006), tienen a menudo tabiques livianos que les restan confort y los hacen ineficientes energéticamente. Eso, y otros defectos funcionales como el uso de diminutas terrazas-tendedero abiertas al exterior, establecen cierta continuidad con las malas prácticas de la dictadura. La oferta de alojamientos mucho más abierta (estudios, apartamentos, dúplex) marca distancias con el pasado, pero se echa en falta una mayor variedad de soluciones formales y habitacionales. 


\section{El reparto de usos y la diversidad funcional}

Aun siendo espacios cuyo cometido principal es la habitación, sus dimensiones y la época en que fueron concebidos permitían esperar un mayor esfuerzo para la integración de usos, aparte de los puramente complementarios (Navarro Vera \& Ortuño Padilla, 2011). Solo en León puede hablarse de verdadera mezcla funcional, y una tasa de actividad considerable. Vigo y La Coruña están más especializados, mientras que el más incompleto es el polígono de Oviedo. En consecuencia, la combinación de funciones diferentes está menos relacionada con el tamaño del barrio que con su centralidad, las actividades preexistentes en sus contornos, el diseño urbanístico y el estatus social. Todos han reequilibrado de algún modo la ciudad, en términos demográficos, pero solo el de Eras de Renueva lo hace económicamente. En efecto, es el único provisto de un sistema diverso y jerarquizado de usos terciarios, que reúnen más de un millar de puestos de trabajo. Son funciones administrativas o culturales de prestigio (Gobierno Regional, Auditorio, Museo de Arte Contemporáneo), en la parte más cualificada por su proximidad al Parador de Turismo de San Marcos. También dispone de oficinas y equipamientos de segundo nivel (Ente Regional de la Energía, Tesorería de la Seguridad Social, Centro de Defensa contra el Fuego), con proyección exterior, así como geriátrico, tanatorio y un centro comercial de tamaño medio, complemento al de mayor categoría existente al otro lado del río.

En los demás casos hay medianas superficies dedicadas a la distribución minorista (Oviedo, Vigo), o grandes cuando se carece de ellas en el entorno, cosa que sucede en La Coruña, donde el centro comercial Los Rosales introduce polaridad y ayuda a rentabilizar la operación inmobiliaria. En las ciudades gallegas son mayoría las funciones de apoyo al alojamiento: escuela municipal, polideportivo, centro cívico, centro de salud, pero no instituto de bachillerato, que sí tienen León y Oviedo. Fuera del comercio, la capacidad de atracción se reduce en La Coruńa al Centro Municipal de Empleo y dos residencias de ancianos; en Vigo, a la Escuela de Arte Dramático y locales de asociaciones. Ahora bien, el polígono vigués mantiene una relación de complementariedad con las áreas limítrofes, particularmente el polígono industrial de Balaídos, donde tienen su empleo algunos residentes en Navia. Dejando a un lado el Instituto de Medicina Legal y el Centro de Estudios Múltiples Dentales, la ausencia de equipamientos de alcance es casi total en Oviedo. Eso guarda conexión con la existencia en un radio próximo de grandes centros de gravitación y empleo: el hospital (Hospital Universitario Central de Asturias, HUCA), el parque comercial Intu Asturias (Ikea, Primark) y dos polígonos industrial-terciarios. Pero allí, al igual que en Vigo, las interacciones espaciales y funcionales entran en conflicto con la segmentación de las diferentes piezas.

La distribución física de los usos no residenciales, incluyendo las zonas verdes, tampoco sigue pautas comunes. La Coruña y Vigo disponen de un gran parque lateral, imbricado con la edificación (Los Rosales) o separado de ella si comparte la mitad occidental del polígono con los servicios (Navia, figura 3). También en La Coruña las dotaciones quedan relegadas a los flancos, y se reservan para el centro comercial los terrenos de contacto con la ciudad consolidada. La otra opción es intercalar los equipamientos con el tejido residencial y los parques y jardines (León), 
de manera que contribuyen según su categoría a definir o separar zonas de distinto estatus. Sin embargo la segregación sociofuncional tampoco es completa, pues el tanatorio está en la parte noble y el gradiente de empobrecimiento al alejarse del centro queda distorsionado, en la medida en que aparecen, a continuación del polígono, urbanizaciones de chalets socialmente exclusivas. La Corredoria es el que ofrece-como ya se dijo- una composición más equilibrada, por el reparto del verde y los espacios públicos, aunque los equipamientos están localizados en el extremo más distante del centro.

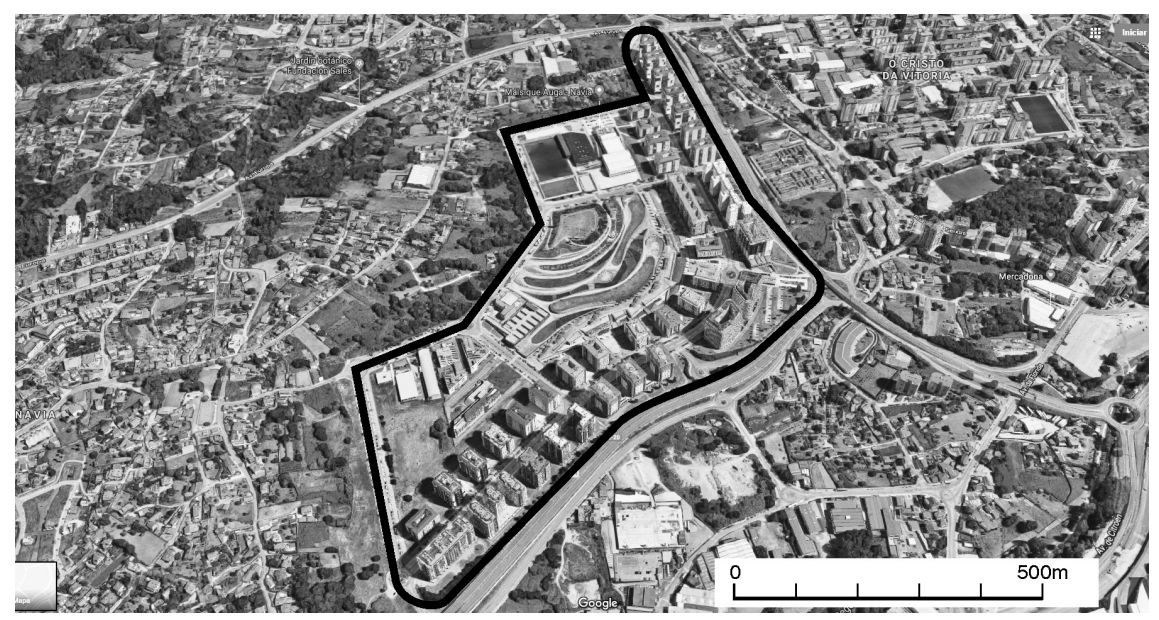

FIgura 3 | Polígono San Paio de Navia (Vigo)

FUENTE: GOOGLE MAPS (20I9) Y ELABORACIÓN PROPIA

El comercio y los servicios de proximidad han proliferado con mayor facilidad allí donde el plano proporciona ejes o nodos de centralidad. El bulevar principal en Vigo, León y La Coruña, asociado este con la gran plaza elíptica, dibuja espacios de relación indisociables del zócalo comercial. La densidad, calidad y especialización de los establecimientos es mayor en Vigo y especialmente La Coruña, trasunto del nivel de renta y la edad media más baja, a pesar del elevado precio de los locales. Este factor, sumado a una población envejecida, solo ha permitido florecer en León un pequeño comercio corriente, fuera del pequeño enclave de concentración hostelera en la parte neurálgica del barrio. La sobrevaloración de los bajos, presente en todos los casos, y un entorno dominado por las rentas bajas, también explica la debilidad del tejido de pequeños negocios en La Corredoria; máxime en ausencia de algo parecido a un eje director, a falta del cual tampoco el entorno de las plazas principales (Cuatro Caños y Conceyín) concentra un gran número de establecimientos cuyo horizonte exceda el abastecimiento vecinal. La falta de perspectivas ha impedido hasta la fecha culminar satisfactoriamente la apertura del mercado de abastos construido en 2010, de manera que va a ser reconvertido en centro cívico (Agudín, 2018). 


\section{Edades, precios y diferencias sociales: unas comunidades relativamente diferenciadas}

Los contingentes poblacionales resultan voluminosos dentro de su contexto: casi 15.000 habitantes en Oviedo, más de 11.000 en León y en torno a 8500 en La Coruña y Vigo. Solo Navia continúa creciendo (10\% desde 2014); los demás están estabilizados, excepto Eras de Renueva, que acusa el declive local y regional en forma de leves pérdidas. En correspondencia con ello, el estereotipo de grandes barrios jóvenes no siempre es aplicable. Con datos de 2017, recogidos por El Confidencial, las edades predominantes por sección censal se situaban en el polígono leonés entre 50 y 54 años, cayendo en su parte trasera de estatus inferior hasta los 45-49. Este es asimismo el grupo dominante en La Coruña, con secciones excepcionalmente definidas por el tramo quinquenal superior (50-54) o inferior (40-44). Los cuarentones son mayoría en La Corredoria, pero el promedio desciende a 35-39 años en su fracción más pobre, resultando un dato global del 31\% de la población por debajo de los 30 años, en 2018. El porcentaje es similar en Vigo (30,25\%, frente a 24,5\% en León), aunque allí la juventud es un atributo más extendido, pues tres quintas partes de las secciones censales de Navia tienen edades medias inferiores a 39 años, sin relación unívoca con la distribución de los precios inmobiliarios (Escudero, 2017).

Las entrevistas certifican que, por regla general, los más jóvenes compraron viviendas para habitarlas o emanciparse, y los mayores para cambiar de residencia o invertir, sin apartarse gran cosa de lo ya conocido en Madrid (Brandis, 2012). Los precios dependen de la situación relativa y la cercanía a elementos de atracción o rechazo, aparte de la calidad material. El juego entre esos factores determina que Navia registre los valores por metro cuadrado más uniformes $(24 \%$ de diferencia máxima), mientras que en León (figura 4) la distancia entre el producto más caro y más barato es de 2,75 veces; el efecto del Parador de San Marcos y los grandes equipamientos genera allí los precios más elevados en $2019\left(3160 € / \mathrm{m}^{2}\right)$. La amplitud entre extremos se acorta en los otros casos: 2,45 veces en Oviedo, 2,27 en La Coruña. Por otro lado, las grandes dimensiones de La Corredoria aportan en sus márgenes los precios más económicos $\left(768 € / \mathrm{m}^{2}\right)$. En el resto están por encima de mil euros, con la salvedad de Los Rosales, donde pueden encontrarse bajos aptos para vivir desde 464 euros $/ \mathrm{m}^{2}$, tras buscar sin éxito usos no residenciales. El reborde exterior es también allí la parte más asequible, en contraposición al hábitat asomado al parque central y el bulevar.

Espaciosos apartamentos en urbanizaciones con piscina, dúplex y lofts alcanzan precios de 335.000 euros en La Coruña y 465.000 en León, cifra esta no tan distante al medio millón, umbral a partir del cual se conceptúan en España las viviendas de lujo cuyos compradores, si son extranjeros, obtienen la nacionalidad española según la Ley 24/2013 de Apoyo a los Emprendedores e Internacionalización. Ese valor máximo de León casi triplica el de Oviedo, y es dos veces y media superior al de Vigo, ciudades en cuyos polígonos el porcentaje de viviendas protegidas (o de precio libre tasado) se sitúa en torno al $90 \%$, siendo los mayores conjuntos de iniciativa oficial dentro de sus municipios. Una proporción inferior al $80 \%$ surte efecto moderador únicamente en el tramo medio bajo de la Eras (León). Pero solo 
puede hablarse de alojamiento relativamente barato en las viviendas de promoción pública y de protección autonómica (VPP y VPA), que suman 700 en La Corredoria y 384 en Navia. Han sido ofrecidas al arriendo, con opción de compra en algún caso, para destinatarios poco solventes que cumplan ciertos requisitos. La cuantía del alquiler en esas viviendas sociales (296 euros en Oviedo por un estudio de 42 $\mathrm{m}^{2}$, incluyendo gastos de comunidad, en abril de 2019) está lejos de los valores de mercado en régimen libre. Dentro de las rentas mensuales predominantes, el intervalo entre mínimo y máximo es más abierto en León (475-760) y La Coruña (500-700) que en Oviedo (480-650), mientras en Vigo la escasa oferta fluctúa entre 650 y 850 euros. Cierta proporción de los alojamientos disponibles incluye garaje y está amueblada, condición también presente en los de precio inferior, mucho más escasos, que normalmente son estudios, plantas bajas, pisos interiores o peor orientados, incluso deteriorados.

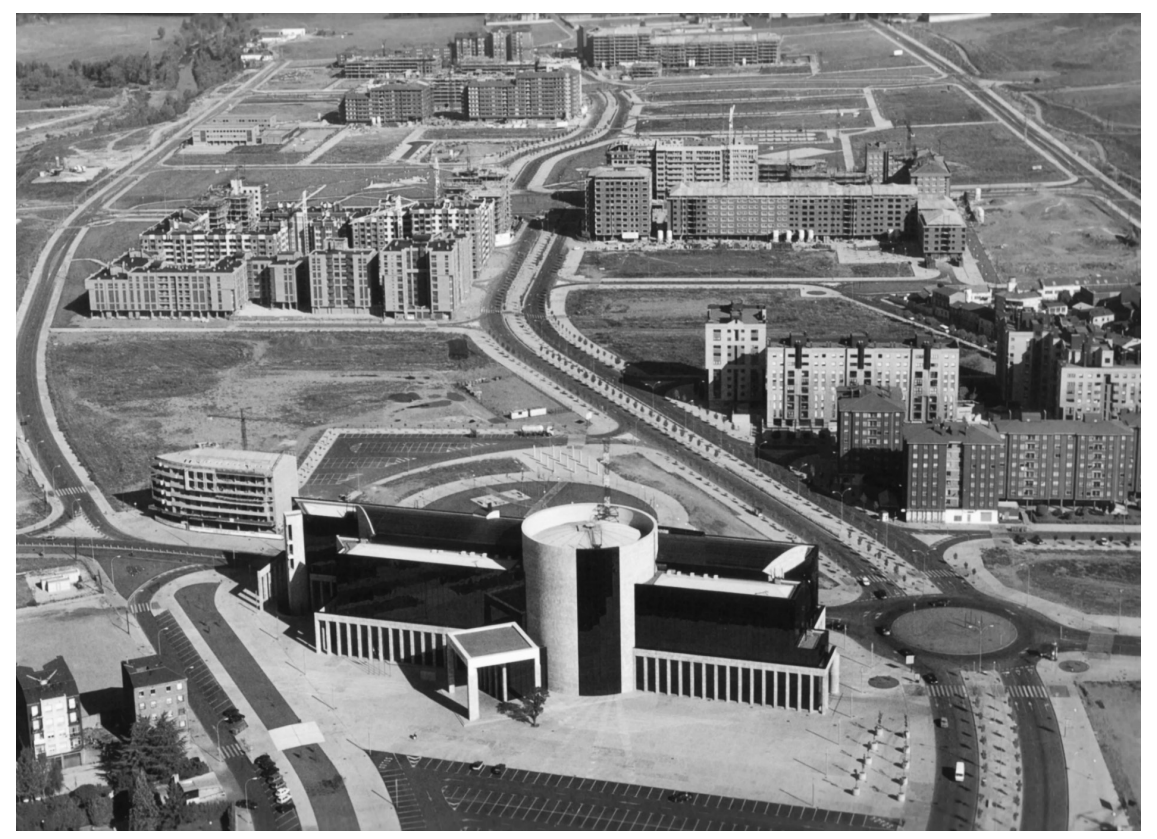

FIgura 4 | Polígono Eras de Renueva (León), en construcción FUENTE: DIARIO DE LEÓN, C. \& R. FOTOGRAFÍA, C. 2003

Inevitablemente la iniciativa oficial ha forjado en alguna medida la identidad del distrito, ha estimulado (aunque no siempre) el movimiento asociativo, relacionado en parte con los déficits urbanísticos, y también ha contribuido localmente a favorecer una cierta marginación social. Según la Agencia Tributaria, la Renta Media Disponible en 2016 fluctúa entre 20.142 euros (La Corredoria) y 22.097 (Los Rosales). ${ }^{2}$ Ese dato oculta las disparidades internas, pero sirve para situar cada polígono en su contexto

2 Navia llega a los 21.875 euros, y se carece de datos sobre León, por no alcanzar los 200.000 habitantes (EpData, 2019). 
local, dentro del cual capacidades adquisitivas no muy dispares cobran significados bien diferentes: el de Oviedo es el segundo barrio más pobre, y en cambio en Vigo hay 14 distritos (sobre un total de 21) cuya renta está por debajo de Navia. En conformidad con ello, menos de un $32 \%$ de la población tiene estudios superiores en el caso asturiano, frente al 43,9-48,3\% del resto, en 2011. Hablar de gueto social resultaría exagerado, pero lo cierto es que La Corredoria, donde gran parte de las calles tienen categoría 5 (sobre 6), cumple los parámetros de vulnerabilidad establecidos por la Unión Europea. Eso le permitió incorporarse a la Iniciativa Urbana (antes Urban), recibiendo fondos europeos para diversos equipamientos (guardería, plaza de abastos) (Ayuntamiento de Oviedo, s.f.). Así las cosas, entra dentro de la lógica que el resultado de las elecciones municipales de 2015 fuera allí favorable a Podemos, igual que en las ciudades gallegas, por el peso de los electores más jóvenes, pero en León el voto estuvo más repartido con las opciones conservadoras.

El sentido de pertenencia y hasta el espíritu u orgullo de barrio están más presentes en las comunidades más homogéneas o de menor edad, pero también se percibe fácilmente en los polígonos más fragmentados un cierto prejuicio clasista entre los habitantes de las partes más caras, hacia los otros residentes; estos suelen incluir el grueso de la comunidad extranjera, nunca muy abultada $(5,65 \%$ en Oviedo, en 2018). El complejo de superioridad puede manifestarse igualmente con respecto a los barrios vecinos más humildes o urbanísticamente más deficientes, como Lugones en Oviedo. La zonificación socioespacial y la jerarquización de los alojamientos parecen indicar que no se ha logrado satisfacer plenamente la aspiración interclasista (Jonas, MacCann, \& Thomas, 2015). Por otro lado, las formas de relación entre vecinos difieren un tanto de los modelos tradicionales en polígonos fordistas, entre otras cosas porque los espacios descubiertos interbloques suelen estar cerrados y no se frecuentan masivamente. Cuando hay una calle o plaza principal, los servicios y el comercio son fuente de animación, incluso dan origen a una especie de paseo popular; de lo contrario las prácticas comunitarias tienen como escenario los centros sociales, zonas verdes y equipamientos, con menos visibilidad en la vía pública. La encuesta reveló que los jóvenes se consideran en todos los casos desatendidos, en cuanto a espacios de socialización y zonas de esparcimiento se refiere, de manera que los suplen cuando es posible por el mall más cercano, o buscan la alternativa en otras partes de la ciudad.

\section{Las debilidades y los problemas urbanos}

El cuestionario destinado a pulsar las opiniones y actitudes de la comunidad, en forma indicativa, se utilizó para entrevistar a una veintena de residentes por localidad. Fueron seleccionados con criterios de paridad, representación generacional ( $25 \%$ de adolescentes, jóvenes, edades medias y mayores de sesenta ańos) y posiciones sociales diferentes (empresario, empleado, obrero, ama de casa, desempleado). 
Pero no tienen papeles prominentes dentro del grupo. ${ }^{3}$ Las asociaciones de vecinos de La Coruña, León y Vigo no mostraron interés al respecto, lo cual se compadece mal en este último caso con el dinamismo de su página web $<$ http://www.paudenavia.es>, y en general indica una falta de tradición participativa fuera de los cauces convencionales. Se descartó, por tanto, la posibilidad de recurrir exclusivamente a las asociaciones de vecinos de Oviedo, o a otros agentes municipales en los cuatro núcleos, pues parecía preferible obtener directamente el diagnóstico del vecindario. Su visión, sustentada en datos objetivos, se nutre igualmente de la experiencia geográfica y la relación perceptiva (individual o de grupo) con el entorno, cuya virtud e interés como fuente de información resulta fácil de contrastar (Lynch, 1977). Como ya se dijo, las cualidades y ventajas más ampliamente reconocidas guardan relación con los precios inmobiliarios algo más asequibles, la calidad del urbanismo medianamente compacto de nueva generación, la provisión de zonas verdes y equipamientos, así como el carácter joven, la relativa uniformidad social y, en términos generales, también la convivencia tranquila y la seguridad.

En cuanto a los aspectos negativos, la tabla 2 recoge las respuestas más reiteradas ( $40 \%$ o más, de los entrevistados), coincidentes en al menos tres de los cuatro barrios analizados. Sobresalen como factores de afección desfavorable la concentración de viviendas públicas, el carácter de barrio separado, que no entabla una relación satisfactoria con sus contornos, y escaso equipamiento urbano. Se responsabiliza de aquello al mal diseño o la insuficiente jerarquización de la red arterial. Hay mención a los problemas de convivencia o el mal ambiente en las zonas de nivel social inferior, pero no al consumo de drogas entre los jóvenes, bastante visible en ciertos casos. Es parecer general que, al concluirse la formación de cada polígono, o mejorar su situación relativa en caso de extenderse la mancha urbana, resulta

3 Encuesta a los vecinos (elaboración propia):

1. ¿Qué cambios ha experimentado el barrio, para mejor y para peor, en los últimos años?

2. ¿Qué problemas y necesidades están pendientes?

3. ¿Qué ventajas tiene vivir allí?

4. ¿Hay identidad de barrio, o sentido de pertenencia? ¿A qué puede deberse?

5. ¿Hay diferencias significativas ente unas partes y otras del barrio?

6. ¿Se han manifestado deficiencias tempranas en la construcción de los edificios o en la urbanización?

7. ¿Cuáles son las más habituales?

8. ¿Conoce la proporción aproximada de viviendas protegidas sobre el total? ¿Qué cooperativas han intervenido?

9. ¿Se ha encarecido con el tiempo la vivienda de forma palpable?

10. ¿Hay una proporción elevada de viviendas en alquiler? ¿Tienen algunas características determinadas?

11. ¿Hay suficiente comercio y servicios de proximidad? ¿Les perjudican las grandes superficies?

12. ¿Se hace vida de relación? ¿Dónde?

13. ¿Hay lugares apropiados para la socialización de los jóvenes? ¿Cuáles?

14. ¿Están bien diseñados los espacios públicos y los jardines? ¿Están bien cuidados?

15. ¿Está resuelto el problema de las guarderías infantiles y escuelas de 0 a 3 ańos?

16. ¿Existen frecuencias suficientes de transporte urbano?

17. ¿Hay una presencia significativa de inmigrantes en determinadas partes del barrio? ¿Conoce la proporción aproximada de viviendas protegidas sobre el total? ¿Qué cooperativas han intervenido? 
inevitable un cierto grado de encarecimiento. Su efecto es visto como ambivalente, valoriza las propiedades pero también agudiza el problema habitacional, y ocupa un lugar central en las dificultades de supervivencia y desarrollo de las pequeñas empresas. La plena ocupación del barrio, por otra parte, pone en evidencia los defectos de planificación del mismo, por ejemplo en cuanto a densidades edificatorias o disponibilidad de plazas de estacionamiento de vehículos, y los déficits relativos a dotaciones y servicios de proximidad (Muńiz, 2005). No hay instituto de bachillerato en Navia, solo se dispone de uno en La Corredoria, incapaz de cubrir las necesidades, y en Eras se carece de centro cívico. La falta de previsión es también palpable en lo tocante a las guarderías municipales.

\begin{tabular}{|c|c|}
\hline CATEGORÍA & NECESIDADES, DEFICIENCIAS Y PROBLEMAS \\
\hline \multirow{5}{*}{$\begin{array}{l}\text { Arquitectura y } \\
\text { urbanismo }\end{array}$} & Mediocre calidad de la edificación del tipo corriente, fallos constructivos. \\
\hline & $\begin{array}{l}\text { Inflación de los precios de venta de viviendas libres y desmesura de los } \\
\text { alquileres. }\end{array}$ \\
\hline & Carestía y desocupación de locales comerciales. \\
\hline & Infrautilización de los bajos. \\
\hline & Espacios libres de tamaño excesivo, sin uso. \\
\hline \multirow{3}{*}{$\begin{array}{l}\text { Dotaciones y economía } \\
\text { local }\end{array}$} & Falta de equipamientos educativos y de proximidad. \\
\hline & Ritmo rápido de sustitución comercial. \\
\hline & Conveniencia de una policía de barrio. \\
\hline \multirow{3}{*}{$\begin{array}{l}\text { Movilidad y } \\
\text { medioambiente }\end{array}$} & Falta de espacios de aparcamiento. \\
\hline & Insuficiencia del transporte público. \\
\hline & Deficiencias en la recogida selectiva de residuos. \\
\hline Participación & Dependencia de las asociaciones de vecinos respecto a los partidos políticos. \\
\hline
\end{tabular}

TABLA 2 Las problemáticas en la percepción ciudadana

FUENTE: ELABORACIÓN PROPIA

Aparte de los extremos ya enumerados, buena parte de las observaciones recogidas se refieren a los constructores y promotores, responsables de una serie de defectos materiales bastante presentes en edificios y pisos de calidad media o baja, aunque no solo en ellos (Martínez, 2016). Grietas, humedades, filtraciones, mala calidad de las obras realizadas en fachadas, y funcionamiento inadecuado de las chimeneas de ventilación en cuartos de baño, son los más fácilmente constatables. Esas deficiencias, añadidas a las disparidades entre lo contratado y lo recibido por los compradores, han dado lugar a reclamaciones y demandas recogidas en la prensa (Rodríguez, 2010). Otra fuente de conflictos ha sido en Vigo el cobro ilegal de sobreprecios en viviendas protegidas, origen de algunas sanciones. ${ }^{4}$ También en Oviedo se denunciaron cobros abusivos en la tarifa del gas y el agua, por parte de la empresa a la que

4 Una de las empresas sancionadas fue Construcuatro, vinculada a un alto cargo del Partido Popular (Agencia EFE, 2018; Rodríguez, 2007). 
el gobierno regional encargó la construcción y gestión de las viviendas públicas en arrendamiento. Allí se ha utilizado el novedoso régimen de "cesión de derecho en superficie", que pone los terrenos (durante medio siglo) en manos de una constructora para que esta edifique los pisos sociales y perciba los alquileres. ${ }^{5}$

Asimismo, están las dimensiones más estrictamente ambientales del urbanismo, como la movilidad, el verde y los espacios públicos. Los encuestados destacaron la oferta insuficiente de plazas de estacionamiento al aire libre, circunstancia que llevó a debatir en Vigo la posibilidad de suprimir zonas verdes, sin éxito. En un segundo plano aparece la intensidad del tránsito rodado que soportan las autovías fronteras a los polígonos, origen de una contaminación acústica muy elevada: el nivel sonoro dB(A) alcanza los 65-70 Lden en algunas calles de La Corredoria (2013), y 70-75 en Navia (2007), sin otra defensa en este caso que una pantalla arbolada (Gobierno de España, s.f.). Frente al ruido y el efecto de barrera, el Ayuntamiento de la ciudad gallega propone el soterramiento, sin proyecto hasta la fecha. Por lo demás, tan solo Oviedo dispone de transporte público de alta capacidad, mediante la estación de acceso a las líneas de cercanías de Renfe y Feve, que sirven al área central de Asturias. El servicio de autobús pierde allí eficiencia por la falta de líneas exprés, aunque sus frecuencias de paso son bajas, como en La Coruña. Por el contrario, Vigo y León tienen intervalos de treinta minutos entre autobuses, con los cuales no puede hablarse de alternativa al automóvil. Al igual que se carece de intercambiadores modales, también la movilidad no motorizada está por desarrollar; solo en Eras de Renueva hay ciclovías, con uso de paseo, y Oviedo tiene proyectado el carril bici desde 2014, sin resultados.

Por lo referido al verde y los espacios públicos, el grado de satisfacción es desigual. La cantidad de suelo dedicada a parques y jardines, incluso huertos de ocio en los polígonos más periféricos (Vigo, Oviedo), es suficiente; pero su incidencia ambiental sería superior de haberse repartido en superficies más reducidas, al estilo de Oviedo, para evitar la ruptura del tejido y el aislamiento que provocan las grandes piezas (López de Lucio, 2007, p. 7). La comunidad critica el insuficiente acondicionamiento de las zonas verdes (parque Nelson Mandela, Vigo) y su escasa cubierta forestal, al predominar los planteamientos de pradera más pobres botánicamente y muy exigentes en agua. Sin embargo, pocos encuestados seńalaron, a propósito de la trama verde, el limitado desarrollo de los árboles de alineación en las aceras, algo relacionado en Galicia con el empleo del soportal. Viales de latitud suficiente carecen de pies de arbolado, o los tienen en escaso número y formación discontinua, cuando no sometidos a podas ornamentales que les impiden cumplir funciones ecológicas. La peor opción es la de renunciar a los árboles de alcorque en las calles donde se encuentran los pisos sociales, cosa que solo sucede en La Corredoria (figura 5). En un mismo orden de cosas, la valoración ciudadana de los espacios libres no ajardinados señala dos defectos principales. Uno es el exceso de superficies embaldosadas o pavimentadas, poco acogedoras, incluso en los patios de manzana o de bloque. El otro es la profusión de elementos barrera (escalones, 
barandillas, verjas, muretes, rampas) en el contacto de las aceras con los edificios, que introducen discontinuidad, dificultan la accesibilidad o privatizan el uso.

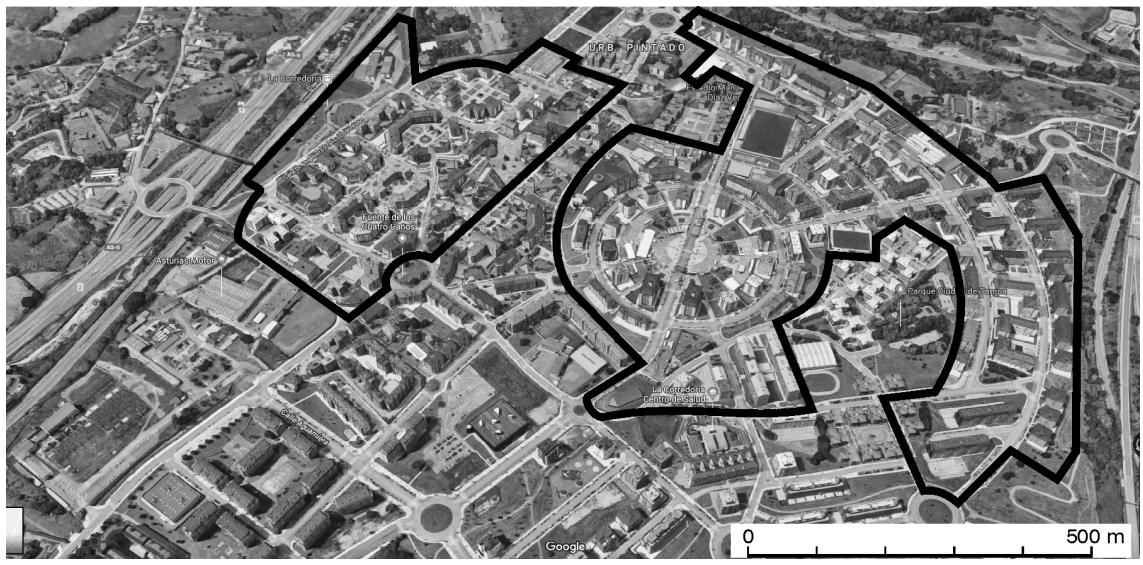

Figura 5 | Polígono de La Corredoria (Oviedo)

FUENTE: GOOGLE MAPS (20I9) Y ELABORACIÓN PROPIA

\section{Conclusiones y discusión}

La Nueva Ciudad incorporada durante el tránsito del siglo xx al xxi fue el último gran proyecto residencial en los núcleos estudiados, cuyo tamaño intermedio y escaso o nulo dinamismo hacen muy improbable la puesta en marcha de otras iniciativas de magnitud equivalente, al menos a mediano plazo. Representó también, aunque no siempre, el último impulso al desarrollo de las viviendas protegidas, relacionado con el florecimiento de las cooperativas, esfuerzo tras el cual se impuso la actual inhibición del Estado (Trilla \& Bosch, 2018). El régimen de protección oficial (y precio libre tasado), más utilizado con carácter general para animar el sector inmobiliario en épocas de atonía o ciclos recesivos, fue también incentivado en capitales de provincia durante la burbuja y el comienzo de la crisis para atender déficits locales heredados y complementar un mercado libre de proporciones modestas. La construcción a cierta escala de alojamientos de distinta modalidad, también libres en todos los polígonos (especialmente León y La Coruña), interesó al capital local y a empresas nacionales (incluso colosos del ramo), las que, al menos en ciertos casos bien documentados, incurrieron en irregularidades, mientras algunas de ellas fueron a la ruina con la crisis. Pero antes ayudaron a disminuir la calidad real de los alojamientos y a encarecer los de venta abierta, reproduciendo en los inmuebles del tipo común malas prácticas heredadas del franquismo.

Aun así, salta a la vista la mayor calidad de esos conjuntos respecto a los polígonos fordistas (densidades edilicias, verde, equipamiento, amplitud del viario). Sin embargo, no siempre se han liberado totalmente de la imagen de barrio (paredones de ladrillo en Oviedo y León, grafitis en Vigo) ni han modernizado por completo su fisonomía, como indica en Oviedo el detalle kitsch de las farolas al 
gusto decimonónico. La polaridad entre dimensiones opuestas es una característica compartida, a propósito de la cual no resulta descabellado identificar el paisajismo como asignatura pendiente. Por otro lado, las condiciones locales son las que determinan la definición final de cada asentamiento e inclinan su evolución en uno u otro sentido, estableciendo diferencias de cierta consideración. Cada uno tiene su registro, según sea la situación geográfica, los valores formales, la composición de clases y la existencia o no de subconjuntos diferenciados; de ahí que sean percibidos en su totalidad o fracciones de distinta forma: buen distrito para vivir, barrio joven, o barrio apartado y de gente relativamente pobre. La comparativa revela que los mejores resultados se obtienen cuando hay buena integración con el entorno urbano, diversidad funcional y mezcla social (Bonard \& Matthey, 2010). Pero esas condiciones no se cumplen por completo prácticamente en ningún caso, por el peso excesivo del uso residencial (La Corredoria es poco más que un barrio dormitorio), la compartimentación física o la fragmentación social. El diseño de los espacios libres no siempre está bien resuelto, como tampoco el engranaje entre lo público y lo privado, ni resultan enteramente satisfactorias las soluciones adoptadas en los bajos de los edificios. El stock de viviendas a precio ascendente, la escasa oferta en alquiler y la abundancia de locales cerrados en algunas ciudades señalan las limitaciones del modelo aplicado y el peso de la especulación. El carácter más o menos exigente o combativo del vecindario puede resultar clave a la hora de introducir las rectificaciones necesarias. Sin ellas, estamos todavía muy lejos de la ciudad sostenible y las experiencias de los ecobarrios ensayadas en otros países europeos (Cohen, 2017). Aparte de lo ya mencionado, fallan las energías alternativas (León será la primera en disponer de una central eléctrica de biomasa), la movilidad dulce, los empleos cercanos y las tramas vegetales complejas (Charlot, 2012; Long, 2015; Veyret \& Le Goix, 2011).

\section{Agradecimientos}

Este artículo es una aportación al Proyecto de Investigación "Paisajes de la desigualdad en las periferias de las ciudades” (referencia PGC 2018-098209-B-100), financiado por el Ministerio de Ciencia, Innovación y Universidades, en la convocatoria 2018 de "Proyectos de I+D de Generación de Conocimiento".

\section{Referencias bibliográficas}

Agencia EFE. (2018, junio 14). El Supremo ratifica la sanción a Construcuatro por sobreprecios en viviendas protegidas. El Correo Gallego. https://www.elcorreogallego. es/galicia/ecg/supremo-ratifica-sancion-construcuatro-precios-viviendas-protegidas/ idEdicion-2018-06-14/idNoticia-1121015

Agudín, R. (2018, febrero 5). La Corredoria, el barrio que es ciudad. El Comercio. https://www. elcomercio.es/oviedo/corredoria-barrio-ciudad-20180205003403-ntvo.html 
Ayuntamiento de Madrid. (2006). Nuevos desarrollos urbanos. https://www.madrid.es/Unidades Descentralizadas/UrbanismoyVivienda/UrbanismoMemoriaDeGestion2006/Actua cionesSingulares/Ficheros/col.pdf

Ayuntamiento de Oviedo. (2017). Clasificación de las vías públicas por categorías a efectos de la aplicación de tributos y precios públicos municipales para el ejercicio 2018.https://www. oviedo.es/CLASIFICACION+VIAS+PUBLICAS.pdf

Ayuntamiento de Oviedo, Ministerio de Economía y Hacienda (s.f.). Iniciativa Urbana (Urban). Oviedo 2007-2013.www.dgfc.sepg.hacienda.gob.es/Iniciativa_Urbana_Ovie do_2007-2013

Belver, M. (2009, septiembre 16). La Corredoria, o donde el agua es más cara que el ladrillo. El Mundo. https://www.elmundo.es/elmundo/2019/09/16/suvivienda/1253098715. html

Bonard, Y. \& Matthey, L. (2010, julio 9). Les écoquartiers, laboratoires de la ville durable? Cybergéo: European Journal of Geography. http://journals.openedition.org/ cybergeo/23202

Borsdorf, A. \& Hidalgo, R. (2010). From polarization to fragmentation. Recent changes in Latin American urbanization. En P.V. Lindert \& O. Verkoren (eds.), Decentralized development in Latin America. Experiences in local governance and local development (pp. 23-34). Dordrecht, Heildelberg, Londres y Nueva York: Springer.

Brandis, D. (2007). Los espacios residenciales españoles en el cambio de siglo. En C. Delgado Viñas (coord.), Espacios públicos, espacios privados. Un debate sobre el territorio (pp. 93130). Bilbao: Universidad de Cantabria y Gobierno de Cantabria.

Brandis, D. (2012). Los grandes desarrollos residenciales en la periferia de Madrid. De la burbuja a la crisis inmobiliaria. En C. Delgado Viñas, J. Juaristi, \& S. Tomé (eds.), Ciudades y paisajes urbanos en el siglo XXI (pp. 241-261). Santander: Studio.

Brandis, D. (2018). Grandes proyectos urbanos y desarrollos residenciales. Del urbanismo de mercado a un nuevo modelo para Madrid. Ciudad y Territorio Estudios Territoriales, (198), 729-745. https://dialnet.unirioja.es/servlet/articulo?codigo=6783275

Burriel de Orueta, E. (2008). La década prodigiosa del urbanismo español. Scripta Nova (12). http://doi.org/10.1344/sn2008.12.1489

Burriel de Orueta, E. (2015). Empty urbanism: the bursting of the Spanish housing bubble. Urban Research \& Practice, 9(2), 158-180. https://doi.org/10.1080/17535069.2015. 1110196

Campesino, A. (2014). Centros y periferias urbanas: ordenación y desgobierno. En R. Lois \& A. Miramontes (eds.), Reflexión sobre las ciudades y el sistema urbano en tiempos de crisis (pp. 91-117). Santiago de Compostela: Universidad de Santiago de Compostela.

Campos Echevarría, J. L. (2008). La burbuja inmobiliaria española. Barcelona: Marcial Pons.

Charlot, A. (2012). Du quartier à la ville durable. Vers un nouveau modèle urbain. Paris: Victoires Éditions.

Cohen, S. (2017). The sustainable city. New York: Columbia University Press.

Cortes de Castilla y León (1993, marzo 30). Diarios de Sesiones (Comisiones), 4693-4720. https://www.sirdoc.ccyl.es/POCCYL/HTMPublicacion. asp?Leg=3\&Serie=DS (C) $\&$ Numero $=185$ 
D.L. (2016, diciembre 28). Vecinos de La Çorredoia denuncian el mal estado de cuatro edificios. El Comercio. https://www.elcomercio.es/oviedo/201612/28/vecinos-corredoria-denun cian-estado-20161228001955-v.html

De la Riva, J.M., Palacios, A.J., \& Vinuesa, J. (2011). Demanda de viviendas, crecimiento residencial y segregación socio-espacial: El caso de los Paus madrileños. En V. Gozálvez $\&$ J. Vinuesa (eds.), Urbanismo expansivo: de la utopía a la realidad. Comunicaciones al XXII Congreso de Geógrafos Españoles (pp. 191-202). Alicante, Universidad de Alicante.

Egea Reche, M. (2000). Tres Cantos en el contexto de las nuevas ciudades. De Actur a municipio independiente (1971-1991). Tesis Doctoral, Universidad Complutense de Madrid. https://eprints.ucm.es/4113/

EpData (2019). Renta bruta por barrios (códigos postales), estadistica y datos de 2016. https:// www.epdata.es/renta-bruta-barrios-codigos-postales-estadistica-datos

Escolano Utrilla, S., López Escolano, C., \& Pueyo-Campos, A. (2018). Urbanismo neoliberal y fragmentación urbana. EURE, 44(132), 183-210. http://doi.org/10.4067/s025071612018000200185

Escudero, J. (2017, febrero 19). ¿Cuál es la edad más habitual de tus vecinos? El Confidencial. https://www.elconfidencial.com/esquema/2017-02-19/edad-mayoritaria-barriosespana-padron_1333798/

Gayo, A. (2013). La Corredoria (Oviedo), un barrio dormitorio de última generación. Trabajo Fin de Grado (inédito). Oviedo, Universidad de Oviedo.

Gobierno de España, Ministerio para la Transición Ecológica (s.f.). Sistema de información sobre Contaminación Acústica (SICA). https://www.sicaweb.cedex.es

Grupo tau \& Liñeiro, A. V. (2016): Ciudad Nueva de Los Rosales-La Coruña. https://www. grupotau.es/2016/06/20/ciudad-nueva-de-los-rosales-a-coruna

Harvey, D. (2007): Breve historia del neoliberalismo. Madrid: Akal.

Jiménez, V., Hidalgo, R., Campesino, A., \& Alvarado, V. (2018). Normalización del modelo neoliberal de expansión residencial más allá del límite urbano en Chile y España. EURE, 44(132), 27-46. http://doi.org/10.4067/SO250-71612018000200027

Jonas, A., MacCann, E., \& Thomas, M. (2015). Urban Geography. A critical introduction. Chichester: Wiley Blackwell.

Long, X. (2015, febrero 2). Analyse géographique des écoquartiers. Innovatio. https://halshs. archives-ouvertes.fr/halshs-01256264

López de Lucio, R. (2004). Morfología y características de las nuevas periferias. Nueve paisajes residenciales en la región urbana de Madrid. Urban, (9), 56-80. https://www.polired. upm.es/index.php/urban/article/view/383

López de Lucio, R. (2007). Construir ciudad en la periferia. Madrid: Mairea Libros.

Lynch, K. (1977). Growing the cities. Cambridge, MA: MIT Press.

Martínez, A. (2016, mayo 21). El 90\% de los edificios de Navia presentan defectos constructivos. La Voz de Galicia. https://www.lavozdegalicia.es/noticia/vigo/vigo/2016/05/21/90edificios-navia-presentan-defectos-constructivos/0003_201605V21C19911.htm

Moreno, F. (s.f.). Polígono Eras de Renueva. https://www.felipe-moreno.com/portfolio/

Muñiz, I. (2005, junio). La Corredoria. Un barrio que se hace oír. Revista Fusión. https://www. revistafusion.com/asturias/junio/report141-4.htm 
Navarro Vera, J. R. \& Ortuño Padilla, A. (2011). Aproximación a la génesis de la contribución de la densidad en la noción de ciudad compacta. EURE, 37(111), 23-41. http://doi. org/10.4067/S0250-71612011000300002

Obeso, Í. (2018). La Corredoria, dinámica reciente de la sexta ciudad de Asturias. En F. Cebrián Abellán (coord.), Ciudades medias y áreas metropolitanas. De la dispersión a la regeneración (pp. 299-315). Cuenca: Universidad de Castilla La Mancha.

Parker, S. (2015). Urban theory and the urban experience. Encountering the city. London \& New York: Routledge.

PAU de Navia. Véase https://www.paudenavia.net

Pinson, G. \& Morel Journel, C. (2016). The neoliberal city-theory, evidence, debates. Territory, Politics, Governance, 4(2), 137-153. http://doi.org/10.1080/21622671.2016.1166982

Precedo, A. \& Míguez, A. (2014). Una radiografía de las ciudades españolas: una evaluación del modelo post industrial. En R. Lois \& A. Miramontes (eds.), Reflexiones sobre las ciudades y el sistema urbano en tiempos de crisis (pp. 15-72). Santiago de Compostela: Universidad de Santiago de Compostela.

Rodríguez, M. (2010, abril 8). Quiebra la promotora de Fadesa que construyó ochocientas viviendas en Os Rosales. La Opinión. https://www.laopinioncoruna.es/ economia/2010/04/08/quiebra-promotora-fadesa-construyo-800-viviendasrosales/373386.html

Rodríguez, M. Á. (2007, marzo 12). Los dueños de los pisos con sobreprecios de Vigo pagaron el doble que los de las cooperativas. La Voz de Galicia. https://www.lavozdegalicia. es/noticia/galicia/2007/03/12/duenos-pisos-sobreprecios-vigo-pagaron-doblecooperativas/0003_5624921.htm

Romero, J. (2010). Construcción residencial y gobierno del territorio en España. De la burbuja especulativa a la recesión. Causas y consecuencias. Cuadernos Geográficos, 47(2), 17-46. https://www.revistaseug.ugr.es/index.php/cuadgeo/article/view/600

Salas, A. (2013, julio 7). Rentas sociales que pesan. El Comercio. https://www.elcomercio. es/v/20130707/oviedo/rentas-sociales-pesan-20130707.html-

Sociedad de Gestión y Promoción de Suelo de Asturias (Sogepsa). La Corredoria-Prado de La Vega. https://www.sogepsa.com/blog/portfolio/prado-de-la-vega/

Suárez, L. (2014, octubre 20). El Principado pone en marcha una nueva fórmula de VPO en Oviedo. Euro Inmo. https://www.euroinmo.com/noticia/19928/autonomias/elprincipado-pone-en-marcha-unanueva-formula-de-vpo-en-oviedo.html

Theodore, N., Peck, J., \& Brenner, N. (2009): Urbanismo neoliberal: la ciudad y el imperio de los mercados. Temas Sociales, 66 (Santiago: SUR), 1-11. http://www.sitiosur.cl/r. php?id $=898$

Trilla, C. \& Bosch, J. (2018). El parque público y protegido de viviendas en España: un análisis desde el contexto europeo. Laboratorio de Alternativas, Documentos de Trabajo (197). https://www.fundacionalternativas.org/laboratorio/documentos/documentos-detrabajo/el-parque-publico-y-protegido-de-viviendas-en-espana-un analisis-desde-elcontexto-europeo

Valcárcel, G. (2013). La ola que arrasó España. Ascenso y crisis de la cultura del ladrillo. Barcelona: RBA. 
Valdunciel, J. (2013). Tipología de las formas de crecimiento del urbanismo expansivo. En Asociación de Geógrafos Españoles, Espacios insulares y de frontera, una visión geográfica. XXIII Congreso de Geógrafos Españoles (pp. 709-718). Palma de Mallorca: Age y Universitat de les Illes Balears.

Vallina, A. (1999). Segregación espacial y social en un barrio de la periferia de Oviedo. La Carisa (1950-1998). Ería, Revista Cuatrimestral de Geografía, (50), 327-346. https:// www.dialnet.unirioja.es/servlet/articulo?codigo $=34897$

Verderber, S. (2012). Sprawling cities and our endangered public health. London \& New York: Routledge.

Veyret, Y. \& Le Goix, R. (2011). Atlas des villes durables. Paris: Autrement. 